\title{
Prothymosin- $\alpha$ plays a defensive role in retinal ischemia through necrosis and apoptosis inhibition
}

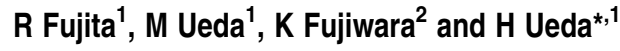

Prothymosin- $\alpha$ (ProT $\alpha$ ) causes a switch in cell death mode from necrosis to neurotrophin-reversible apoptosis in primary cultured cortical neurons. In the present study, post-ischemic administration ( 3 or $24 \mathrm{~h}$, intravenously) of recombinant mouse ProT $\alpha$ without neurotrophins completely prevented ischemia-induced retinal damage accompanying necrosis and apoptosis, as well as dysfunction assessed by electroretinogram. Treatments with anti-erythropoietin (EPO) or brain-derived neurotrophic factor (BDNF) immunoglobulin G (IgG) reversed ProT $\alpha$-induced inhibition of apoptosis. ProT $\alpha$ upregulated retinal EPO and BDNF levels in the presence of ischemia. Moreover, intravitreous administration of anti-ProT $\alpha \operatorname{lgG}$ or an antisense oligodeoxynucleotide for ProT $\alpha$ accelerated ischemia-induced retinal damage. We also observed that ischemia treatment caused a depletion of ProT $\alpha$ from retinal cells. Altogether, these results suggest that the systemic administration of ProT $\alpha$ switches ischemia-induced necrosis to apoptosis, which in turn is inhibited by neurotrophic factors upregulated by ProT $\alpha$ and ischemia. ProT $\alpha$ released upon ischemic stress was found to have a defensive role in retinal ischemia.

Cell Death and Differentiation (2009) 16, 349-358; doi:10.1038/cdd.2008.159; published online 7 November 2008

Ischemic stress in the central nervous system causes both necrosis, which occurs first in the ischemic core, and apoptosis, which occurs following necrosis in the region surrounding the core, called the penumbra. ${ }^{1-3}$ Necrosis, which accompanies cell membrane destruction, is followed by the release of intracellular cytotoxic substances that cause cell death expansion, whereas apoptosis occurs after some delay, but may also have a potential role in restricting the spread of irretrievable damage in the penumbra, as microglia phagocytize apoptotic neurons without releasing cytotoxic substances. Although several compounds that inhibit apoptosis have been reported to be protective against ischemic damage in vivo, their potencies are limited, ${ }^{4-7}$ possibly because the necrotic region becomes enlarged at a relatively early stage. Thus, necrosis could be a most important target for treating ischemic damage.

We previously demonstrated that a switch in cell death mode occurs when cortical neurons are cultured under serumfree conditions without any supplements. Specifically, cortical neurons die by necrosis when cultured at low densities, but die by apoptosis after some delay when cultured at high densities. ${ }^{8,9}$ Recently, we identified a molecule, prothymo$\sin -\alpha$ (ProT $\alpha$ ), which is responsible for the density-dependent cell death mode switch, by analyzing factors in conditioned media derived from high-density cultures. ${ }^{10}$ Detailed analysis revealed that ProT $\alpha$ inhibits necrosis by reversing the decreased externalization of the glucose transporters GLUT1 and GLUT4, through the activation of protein kinase $\mathrm{C} \beta_{2}$ $\left(\mathrm{PKC} \beta_{2}\right)$, while causing apoptosis by upregulating the proapoptotic proteins Bax and Bim through activation of $\operatorname{PKC} \beta_{1}$ and $\beta_{2}$. More recently, we demonstrated that ProT $\alpha$ strongly prevents ischemia-induced damage after rat middle cerebral artery occlusion. ${ }^{11}$ In that study, ProT $\alpha$ inhibited both necrotic and apoptotic cell death in vivo, in contrast with the fact that this protein caused apoptosis in a culture study. ${ }^{10}$ However, the machineries underlying this difference remain to be determined.

The retina is a part of the central nervous system that is easily accessible for quantitative analysis of pathophysiological processes and experimental manipulation. ${ }^{12}$ Transient ischemia-induced damage of the retina, as well as of the brain, results in a prolonged period of neuronal cell death. The mechanisms of ischemia-induced neuronal cell death include an early phase of excitotoxicity through glutamate, leading to necrosis, and a prolonged phase of apoptosis. ${ }^{13,14}$ This model seems to be ideal for characterizing the in vivo effects and roles of ProT $\alpha$ in terms of gain-of-function and loss-of-function, as it causes both necrosis and apoptosis, and drug manipulation is very easy. The present study shows that ProT $\alpha$ causes a switch in cell death mode in an in vivo retinal ischemia model, and that it inhibits cell death expansion.

\footnotetext{
${ }^{1}$ Division of Molecular Pharmacology and Neuroscience, Nagasaki University Graduate School of Biomedical Sciences, Nagasaki, Japan and ${ }^{2}$ Department of Applied Life Science, Faculty of Biotechnology and Life Science, Sojo University, Kumamoto, Japan

${ }^{*}$ Corresponding author: H Ueda, Division of Molecular Pharmacology and Neuroscience, Nagasaki University Graduate School of Biomedical Sciences, 1-14 Bunkyomachi, Nagasaki 852-8521, Japan. Tel: + 8195819 2421; Fax: + 8195819 2420; E-mail: ueda @ nagasaki-u.ac.jp

Keywords: ischemia; necrosis; apoptosis; prothymosin- $\alpha$; BDNF and retina

Abbreviations: AS-ODN, antisense oligodeoxynucleotide; BDNF, brain-derived neurotrophic factor; EPI, epithelial cell layer; EPO, erythropoietin; ERG, electroretinogram; GCL, ganglion cell layer; IgG, immunoglobulin G; i.v., intravenous administration; i.vb, intravitreous administration; INL, inner nuclear layer; IPL, inner plexiform layer; MS-ODN, missense oligodeoxynucleotide; ONL, outer nuclear layer; PI, propidium iodide; rmProT $\alpha$, recombinant mouse prothymosin- $\alpha$; TEM, transmission electron microscopy

Received 14.4.08; revised 04.9.08; accepted 06.10.08; Edited by GP Gasic; published online 7.11.08
} 
Results

ProT $\alpha$-induced prevention of histological and functional retinal ischemic damage. When mouse eyes were subjected to hydrostatic pressure $(130 \mathrm{~mm} \mathrm{Hg})$ for $45 \mathrm{~min}$ followed by reperfusion, the thicknesses of retinal cell layers, namely the ganglion cell layer (GCL), the inner nuclear layer (INL) and the outer nuclear layer (ONL), decreased in a timedependent manner (Figure 1a and Table 1). The maximal decrease was attained on day 7 after ischemic-reperfusion stress, and no further damage was observed on day 14. This decrease in thickness was mostly attributable to damage to the inner plexiform layer (IPL) fibers. Intravitreous (i.vb.) application of recombinant mouse ProT $\alpha$ ( $r$ ProT $\alpha) 30 \mathrm{~min}$ before the stress, or 3 or $24 \mathrm{~h}$ after the stress, prevented this decrease in the thickness of layers (Figure 1a and Table 1). Systemic intravenous (i.v.) administration of $\mathrm{rmProT} \alpha$ at $100 \mu \mathrm{g} / \mathrm{kg} 3 \mathrm{~h}$ after the stress also provided complete protection. In electroretinograms (ERGs), the amplitudes called a-waves (indicated in Figure 1b) are known to represent the function of photoreceptor cells, whereas b-waves represent the functions of bipolar and Muller cells. ${ }^{15}$ On day 7 after ischemic stress, the a- and b-wave amplitudes were markedly decreased to approximately 25 and $15 \%$, respectively, of those in sham-operated and vehicle-treated control animals, as shown in Figure 1c and d. This functional damage was significantly prevented by local (i.vb.) or systemic (i.v.) application of $\mathrm{rmProT} \alpha$ in a dose-dependent manner. To examine the retinal transport of $\mathrm{rmProT} \alpha$, biotinylated $\mathrm{rmProT} \alpha$ was administered at $1 \mathrm{mg} / \mathrm{kg}$ (i.v.) $3 \mathrm{~h}$ after ischemia and reperfusion. As shown in Figure 1e, a significant amount of biotinylated $\operatorname{rmProT} \alpha$ was detected in the retina $6 \mathrm{~h}$ after reperfusion. However, negligible amounts of biotinylated $\mathrm{rmProT} \alpha$ were detected in the preparations from sham-operated mice.

Necrosis precedes apoptosis following ischemic stress. By transmission electron microscopy (TEM) analysis, the cell morphology is different between INL and ONL cells. In the INL, cell-cell adhesion is very tight (low magnification), the nuclei occupy most of the space in cells (middle magnification) and mitochondria have clear cristae (high magnification) (Figure 2a). In the ONL, cells show very high electron density in central nuclei and characteristic lower-density regions at their edges. As early as day 1 after ischemic stress, INL and ONL cells died by necrosis, which was characterized by a loss of electron density in the cytosol and swollen mitochondria without nuclear condensation (Figure 2a, arrowhead). Three days after the stress, necrotic cells disappeared, but apoptosis, which was characterized by nuclear fragmentation or condensation,
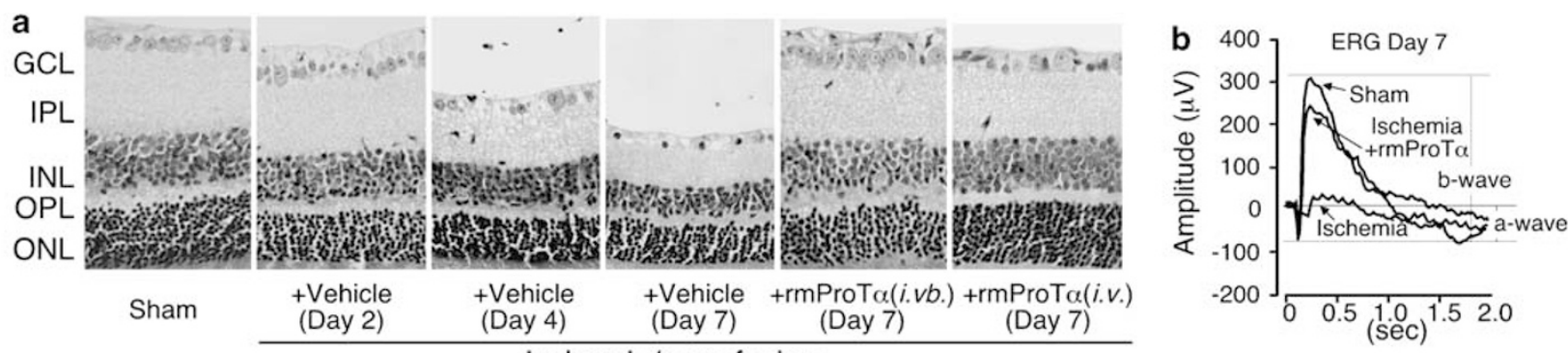

Ischemia/reperfusion
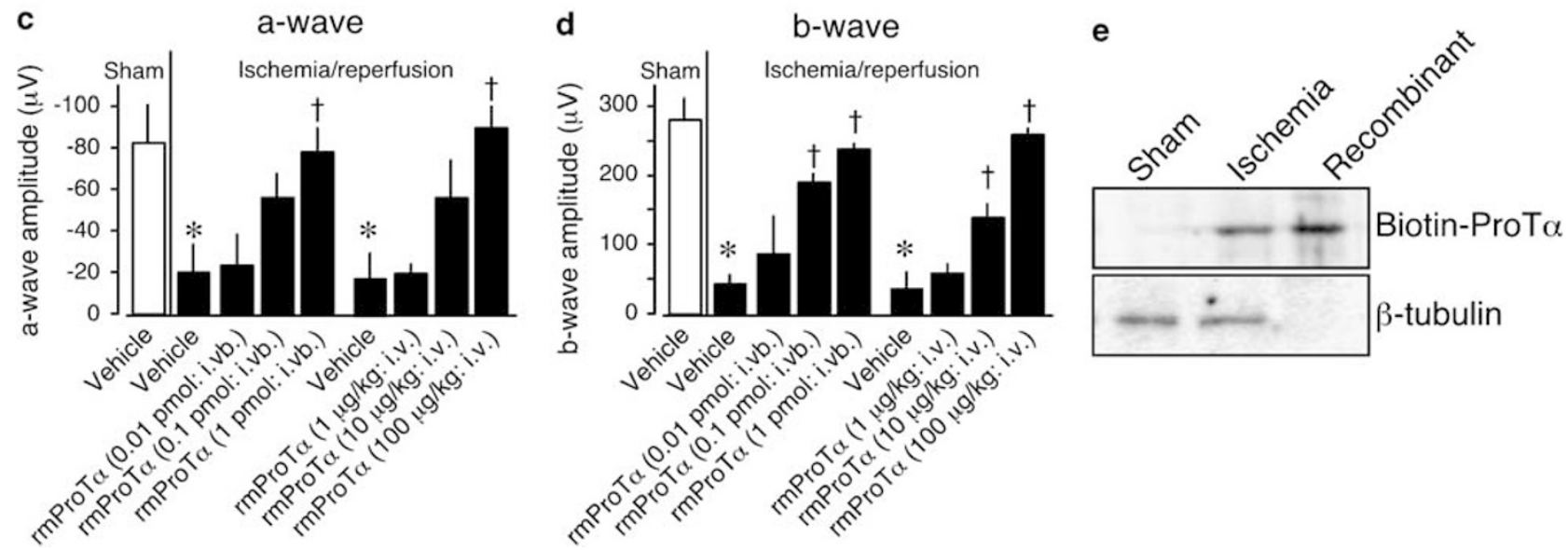

Figure 1 ProT $\alpha$ prevents retinal ischemia-induced necrosis and apoptosis. (a) H\&E staining of retinal sections at days 2,4 and 7 after ischemia and reperfusion. rmProT $\alpha$ $(100 \mu \mathrm{g} / \mathrm{kg}$, i.v.) was administered at $24 \mathrm{~h}$ after retinal ischemic stress. (b) ERG recordings at day 7 after ischemic stress. rmProT $\alpha$ was given at $24 \mathrm{~h}$ after the stress. Results represent the means \pm S.E.M. of 6 independent experiments. (c and d) Dose-dependent prevention of retinal ischemic damage evaluated by a- (c) and b- (d) wave ERG analysis. ProT $\alpha(0.01-1 \mathrm{pmol}$ i.vb. or $1-100 \mu \mathrm{g} / \mathrm{kg}$, i.v.) was administered $24 \mathrm{~h}$ after retinal ischemic stress. The results were evaluated on the basis of a- and $\mathrm{b}$-wave amplitudes, and represent the means \pm S.E.M. of six independent experiments. ${ }^{\star} P<0.05$ versus sham. ${ }^{\dagger} P<0.05$ versus ischemia vehicle treatment. (e) Evidence for biotinylated ProT $\alpha$ transport through the blood-retina barrier after ischemic stress. Biotinylated ProT $\alpha$ at $1 \mathrm{mg} / \mathrm{kg}$ (i.v.) was given to mice $3 \mathrm{~h}$ after reperfusion. Proteins ( $50 \mu \mathrm{g}$ ) from the retina were isolated $3 \mathrm{~h}$ after administration and then used for western blot analysis 
Table 1 ProT $\alpha$-induced prevention of retinal neuron damage under ischemic conditions

\begin{tabular}{|c|c|c|c|c|}
\hline Treatment & Days after ischemia/reperfusion & GCL & INL & ONL \\
\hline Control & 0 & $18.23 \pm 3.24$ & $113.05 \pm 5.11$ & $303.64 \pm 42.38$ \\
\hline Sham+vehicle & 7 & $16.61 \pm 1.12$ & $123.02 \pm 5.91$ & $296.69 \pm 28.37$ \\
\hline Ischemia+vehicle & 2 & $14.63 \pm 0.88$ & $110.60 \pm 15.61$ & $222.20 \pm 6.98^{*}$ \\
\hline Ischemia+vehicle & 4 & $7.82 \pm 3.56^{*}$ & $88.95 \pm 12.84^{*}$ & $171.56 \pm 19.62^{*}$ \\
\hline Ischemia+vehicle & 7 & $5.37 \pm 0.30^{*}$ & $75.37 \pm 3.76^{*}$ & $147.54 \pm 7.09^{\star}$ \\
\hline Ischemia+vehicle & 14 & $6.30 \pm 0.48^{*}$ & $72.63 \pm 3.64^{*}$ & $144.51 \pm 4.44^{\star}$ \\
\hline Sham+ProT $\alpha(-0.5 \mathrm{~h}, 1 \mathrm{pmol}$, i.vb.) & 7 & $15.84 \pm 1.99$ & $133.01 \pm 2.15$ & $273.80 \pm 19.66$ \\
\hline Ischemia+ProT $\alpha(-0.5 \mathrm{~h}, 0.01 \mathrm{pmol}, \mathrm{i} . \mathrm{vb})$. & 7 & $6.35 \pm 0.38$ & $82.56 \pm 5.16$ & $135.86 \pm 8.85$ \\
\hline Ischemia+ProT $\alpha(-0.5 \mathrm{~h}, 0.1 \mathrm{pmol}$, i.vb.) & 7 & $11.57 \pm 1.50^{\#}$ & $104.53 \pm 6.50^{\#}$ & $217.02 \pm 1.59^{\#}$ \\
\hline Ischemia+ProT $\alpha(-0.5 \mathrm{~h}, 1 \mathrm{pmol}$, i.vb.) & 7 & $14.74 \pm 0.67^{\#}$ & $116.33 \pm 0.88^{\#}$ & $270.06 \pm 9.54^{\#}$ \\
\hline Ischemia+ProT $\alpha$ (3h, 0.01 pmol, i.vb.) & 7 & $4.94 \pm 2.21$ & $71.53 \pm 3.38$ & $144.23 \pm 12.25$ \\
\hline Ischemia+ProT $\alpha$ (3h, 0.1 pmol, i.vb.) & 7 & $12.31 \pm 0.25^{\#}$ & $83.82 \pm 4.23$ & $222.31 \pm 4.70^{\#}$ \\
\hline Ischemia+ProT $\alpha$ (3h, 1 pmol, i.vb.) & 7 & $14.24 \pm 0.48^{\#}$ & $101.63 \pm 5.12^{\#}$ & $286.01 \pm 5.48^{\#}$ \\
\hline Ischemia+ProT $\alpha(24 \mathrm{~h}, 0.1 \mathrm{pmol}$, i.vb.) & 7 & $6.86 \pm 0.95$ & $84.55 \pm 3.68$ & $138.61 \pm 2.85$ \\
\hline Ischemia+ProT $\alpha$ (24 h, 1 pmol, i.vb.) & 7 & $10.62 \pm 0.25^{\#}$ & $95.27 \pm 4.85^{\#}$ & $245.28 \pm 5.24^{\#}$ \\
\hline Ischemia+ProT $\alpha(-0.5 \mathrm{~h}, 1 \mu \mathrm{g} / \mathrm{kg}$, i.v.) & 7 & $5.51 \pm 1.25$ & $75.83 \pm 3.64$ & $158.21 \pm 8.25$ \\
\hline Ischemia+ProT $\alpha(-0.5 \mathrm{~h}, 10 \mu \mathrm{g} / \mathrm{kg}$, i.v. $)$ & 7 & $10.86 \pm 2.28^{\#}$ & $88.57 \pm 6.56^{\#}$ & $172.87 \pm 6.85^{\#}$ \\
\hline Ischemia+ProT $\alpha(-0.5 \mathrm{~h}, 100 \mu \mathrm{g} / \mathrm{kg}$, i.v. $)$ & 7 & $12.30 \pm 2.32^{\#}$ & $110.82 \pm 6.65^{\#}$ & $258.59 \pm 5.28^{\#}$ \\
\hline Ischemia+ProT $\alpha(3 \mathrm{~h}, 1 \mu \mathrm{g} / \mathrm{kg}$, i.v. $)$ & 7 & $4.91 \pm 2.35$ & $72.23 \pm 2.86$ & $142.66 \pm 5.28$ \\
\hline Ischemia+ProT $\alpha(3 \mathrm{~h}, 10 \mu \mathrm{g} / \mathrm{kg}$, i.v. $)$ & 7 & $12.61 \pm 3.66^{\#}$ & $108.60 \pm 5.58^{\#}$ & $196.54 \pm 12.84^{\#}$ \\
\hline Ischemia+ProT $\alpha(3 \mathrm{~h}, 100 \mu \mathrm{g} / \mathrm{kg}$, i.v. $)$ & 7 & $15.27 \pm 1.41^{\#}$ & $112.41 \pm 7.53^{\#}$ & $236.95 \pm 7.09^{\#}$ \\
\hline Ischemia+ProT $\alpha(24 \mathrm{~h}, 10 \mu \mathrm{g} / \mathrm{kg}$, i.v. $)$ & 7 & $5.23 \pm 3.26$ & $78.56 \pm 4.85$ & $135.81 \pm 6.64$ \\
\hline Ischemia+ProT $\alpha(24 \mathrm{~h}, 100 \mu \mathrm{g} / \mathrm{kg}$, i.v. $)$ & 7 & $13.23 \pm 0.84^{\#}$ & $104.29 \pm 3.68^{\#}$ & $201.22 \pm 4.65^{\#}$ \\
\hline
\end{tabular}

Abbreviations: GCL, ganglion cell layer; INL, inner nuclear layer; i.v., intravenous; ONL, outer nuclear layer.

${ }^{\star} P<0.05$ versus sham; ${ }^{\#} P<0.05$ versus ischemia vehicle treatment

a

a

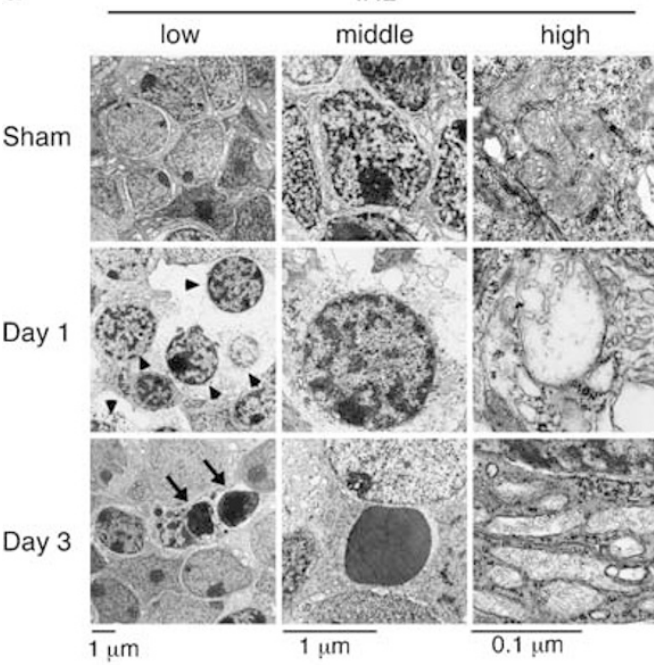

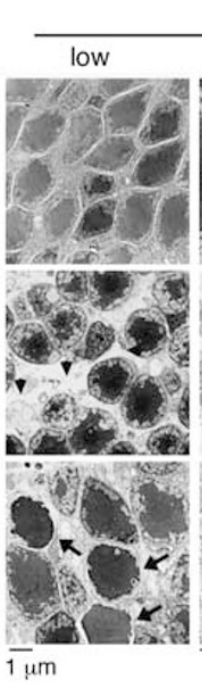

ONL

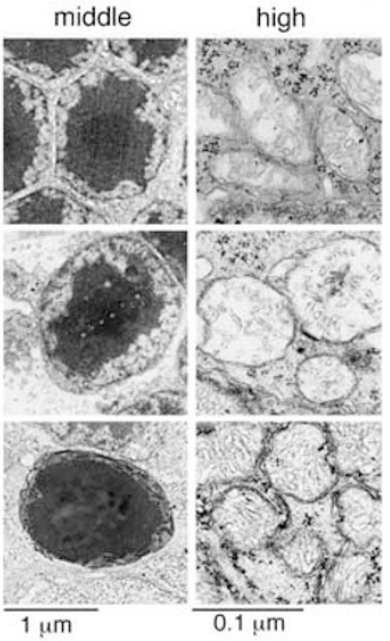

C
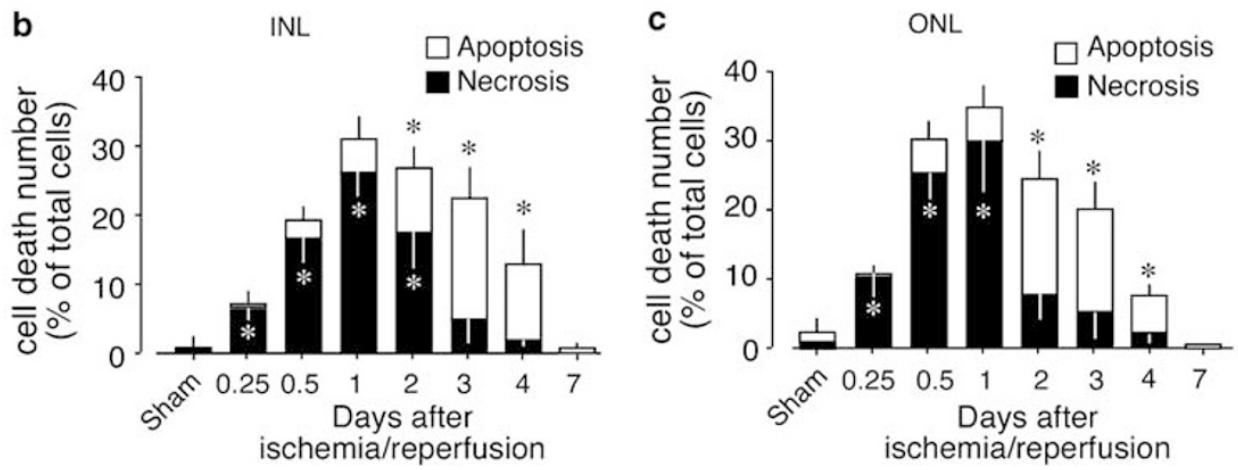

Figure 2 Necrosis precedes apoptosis after ischemic stress. (a) TEM analysis of the INL (left) and ONL (right). At days 1 and 3 after ischemia and reperfusion, necrosis is characterized by membrane destruction and loss of electron density in the cytosol (arrowheads). Apoptosis is characterized by nuclear condensation (arrow). (b and $\mathbf{c}$ ) Quantitative comparisons in terms of the cell populations showing necrotic and apoptotic features in the TEM analysis in (a). Results represent the means \pm S.E.M. of four independent experiments. ${ }^{*} P<0.05$ versus sham 
a
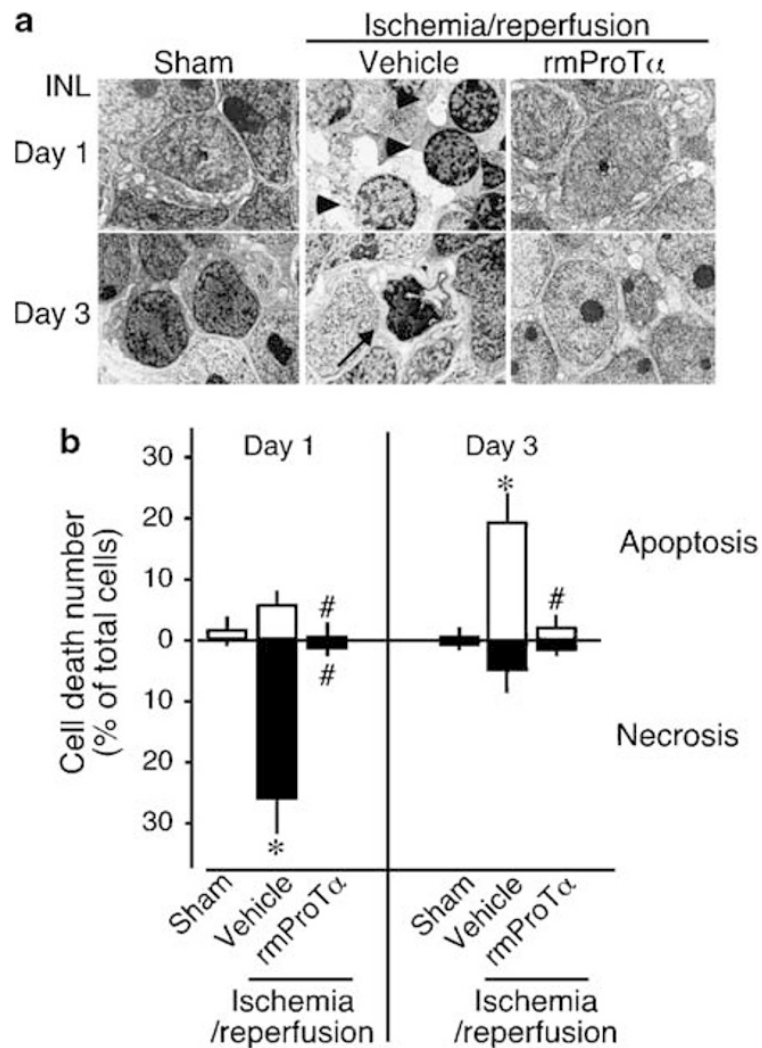

Figure 3 ProT $\alpha$ prevents retinal ischemia-induced necrosis and apoptosis. (a) TEM analysis of the INL. rmProT $\alpha(100 \mu \mathrm{g} / \mathrm{kg}$, i.v. $)$ was administered $3 \mathrm{~h}$ after retinal ischemic stress and the retina was isolated 1 or 3 day after the stress. (b) Quantitative comparisons in terms of the cell populations showing necrotic (closed column) and apoptotic (open column) features in the TEM analysis in (a). Results represent the means \pm S.E.M. of $4-6$ independent experiments. ${ }^{*} P<0.05$ versus sham. ${ }^{\#} P<0.05$ versus ischemia vehicle treatment

appeared instead (Figure 2a, arrow). However, mitochondrial swelling was not observed. Time-course studies revealed that the maximum incidence of necrosis in the INL and ONL was observed at day 1 , although that of apoptosis occurred at day 3 after ischemic stress, as shown in Figure $2 \mathrm{~b}$ and $\mathrm{c}$.

As shown in Figure $3 a$ and $b$, we confirmed that intravenous administration of rmProT $\alpha$ at $100 \mu \mathrm{g} / \mathrm{kg}$ (i.v.) $3 \mathrm{~h}$ after ischemic stress completely inhibited necrosis by TEM analysis. This treatment also abolished apoptosis.

ProT $\alpha$-induced inhibition of necrotic and apoptotic cell death. Propidium iodide (PI) staining has been used as a marker for necrosis due to plasma membrane damage. ${ }^{.6}$ In the present retinal system, in vivo pretreatment with $\mathrm{PI}$ is relatively easy, as it can be intravitreously administered $30 \mathrm{~min}$ before isolation of the retina. No significant signal was observed throughout the sham-operated retina, except in the epithelial layer (EPI), which is liable to be damaged and artificially stained with $\mathrm{PI}$ during the process of sample preparation. When hydrostatic pressure was given to the retina, marked PI staining was observed in the ONL as early as $6 \mathrm{~h}$ (day 0.25) after stress, and subsequently, in the INL and GCL at days 0.5 and 1 , respectively. However, the PI signals substantially disappeared thereafter until day 3
(Figure 4a), possibly due to lysis of the dead cells. Quantitative analyses using $\mathrm{NIH}$ Image software revealed that the maximal PI signals in the retinal region, including the GCL, INL and ONL, but not the EPI, were observed at day 1 after the stress (Figure 4b). Systemic administration of $\mathrm{rmProT} \alpha$ at $100 \mu \mathrm{g} / \mathrm{kg}$ (i.v.) $30 \mathrm{~min}$ before the stress thoroughly inhibited retinal ischemia and reperfusioninduced PI staining for 3 days.

As shown in Figure $5 \mathrm{a}$, apoptosis activity measured by terminal deoxyribonucleotidyl transferase-mediated dUTPbiotin nick end labeling (TUNEL) staining, which detects DNA double strand brake in apoptosis, was strongly observed at day 3 in the ONL, INL and GCL; moreover, on days 1 and 5 after the stress, weak signals were seen in the ONL and INL. Caspase-3 activation has also been used to characterize apoptosis. As shown in Figure $5 \mathrm{~b}$, caspase-3-like protease activity, which digests the substrate acetyl-DEVD-aminomethylcoumarin (Ac-DEVD-MCA) to release the fluorescent aminomethylcoumarin, showed no significant increases in the sham-operated retina. A marked increase in this activity was detected in the ischemia and reperfusion-treated retina at day 3 , but not before or after this time. Systemic administration of rmProT $\alpha 30 \mathrm{~min}$ before the stress completely prevented the retinal apoptosis induced by ischemia and reperfusion up to day 5. Active caspase-3-like immunoreactivity has also been used to characterize apoptosis. A strong signal was detected in the ONL optic disc and INL, specifically, at day 3 , but not before or after this time, as shown in Supplementary Figure 1a. Systemic administration of $\mathrm{rmProT} \alpha 30 \mathrm{~min}$ before the stress completely prevented retinal apoptosis induced by ischemia and reperfusion at day 5. Quantitative analyses using NIH ImageJ software revealed that maximum activecaspase-3 immunoreactivities were observed as late as day 3 after the ischemic stress (Supplementary Figure 1b).

Involvement of neurotrophins in ProT $\alpha$-induced retinoprotection against ischemic damage. Weak brain-derived neurotrophic factor (BDNF) immunoreactivities were observed in the INL, IPL, ONL and ONL optic disk (Figure 6a). Ischemic stress elevated the BDNF level in the GCL at $24 \mathrm{~h}$ after the stress, without substantial changes in the other cell layers. The administration of $\mathrm{rmProT} \alpha$ at $100 \mu \mathrm{g} / \mathrm{kg}$ (i.v.) enhanced BDNF expression throughout the retinal layers (GCL, INL and ONL optic disk). However, rmProT $\alpha$ alone, without ischemia treatment had no effect (data not shown), though it remains unclear whether the lack of change is attributed to poor transportation into the retina without ischemia. Moreover, erythropoietin (EPO) expression was elevated in the GCL after ischemic stress, with no substantial changes in other cell layers. ProT $\alpha$ administration did not change the EPO levels in the GCL or INL, but increased the level in the ONL optic disc. Western blot analysis confirmed that ProT $\alpha$ plus ischemic stress caused significant elevations of mature BDNF and EPO, but not nerve growth factor or basic fibroblast growth factor (bFGF), in the retina (Figure $6 \mathrm{~b}$ and Supplementary Figure 2). As shown in Figure 6c, the apoptosis activity measured by TUNEL staining was weak, but significant in the ONL layer as early as day 1 after the stress. Systemic (i.v.) injection of ProTa markedly inhibited both necrotic PI and apoptotic TUNEL staining throughout the retina. It should be noted that ProT $\alpha$ 
a

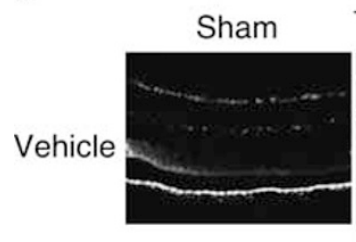

ProT $\alpha$ (i.v.) $100 \mu \mathrm{g} / \mathrm{kg}$

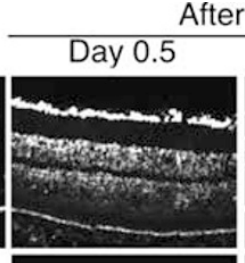

After ischemia/reperfusion
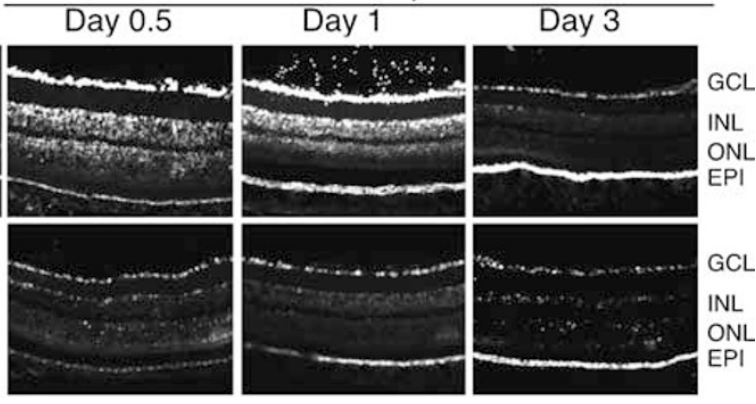

b

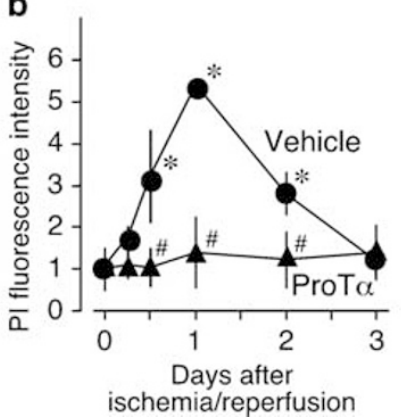

Figure 4 Time course of PI staining of retinas after ischemia and reperfusion under the ProT $\alpha$-treated condition. (a) PI staining of retinal sections at the indicated time points after ischemia and reperfusion. GCL: ganglion cell layer, INL: inner nuclear layer, ONL: outer nuclear layer and EPI: epithelial cell layer. (b) Fluorescence intensities were analyzed using NIH Image. ${ }^{*} P<0.05$ versus 0 day. As the PI signal in the EPI is observed in the preparation without ischemia, we did not include the change in this layer in the evaluation of cell death. Results represent the means \pm S.E.M. of $4-6$ independent experiments. ${ }^{\#} P<0.05$ versus ischemia vehicle treatment

a

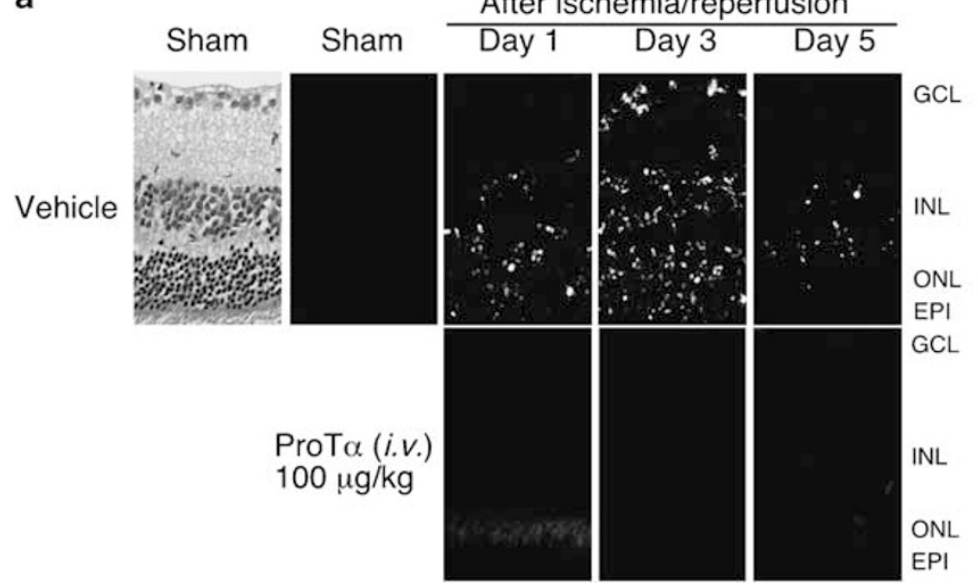

After ischemia/reperfusion

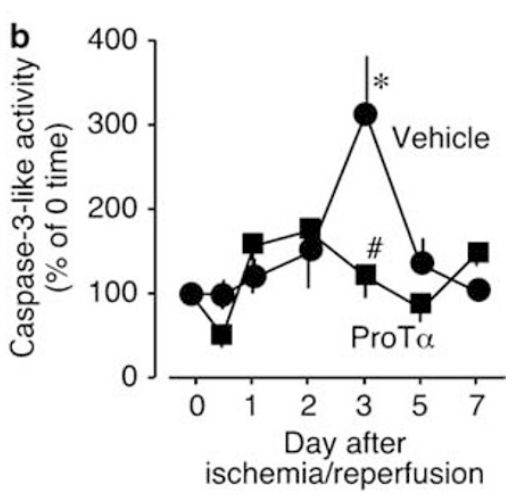

Figure 5 Time course of apoptotic cell death of retinas after ischemia and reperfusion under the ProT $\alpha$-treated condition. (a) TUNEL staining of retinal sections at the indicated time points after ischemia and reperfusion. rmProT $\alpha(100 \mu \mathrm{g} / \mathrm{kg}$, i.v.) was administered $3 \mathrm{~h}$ after retinal ischemic stress. GCL: ganglion cell layer, INL: inner nuclear layer, ONL: outer nuclear layer and EPI: epithelial cell layer. (b) Caspase-3-like activity of retinal cells at the indicated time points after ischemia and reperfusion. rmProT $\alpha$ $(100 \mu \mathrm{g} / \mathrm{kg}$, i.v. $)$ was administered $3 \mathrm{~h}$ after retinal ischemic stress. Results represent the means \pm S.E.M. of $4-6$ independent experiments. ${ }^{*} P<0.05$ versus day $0 .{ }^{\#} P<0.05$ versus ischemia vehicle treatment

inhibited both necrosis and apoptosis following retinal ischemia. This finding contrasts with our recent study, in which ProT $\alpha$ was shown to inhibit necrosis, but to cause apoptosis. ${ }^{10}$ However, complete inhibition of cell death was observed when ischemic neurons were cotreated with ProT $\alpha$ and anti-apoptotic neurotrophins, the expression levels of which are upregulated in this model (Figure $6 \mathrm{a}$ and $\mathrm{b}$ ). In fact, when anti-BDNF or anti-EPO immunoglobulin G (IgG; $1 \mu \mathrm{g}$ per eye) was intravitreously administered $30 \mathrm{~min}$ before ischemic stress,
TUNEL staining reappeared more intensely than in the vehicle control, but no significant change in the intensity of $\mathrm{PI}$ staining was observed (Figure $6 c$ and $d$ ). However, these anti-IgG treatments alone had no effect on the levels of either necrosis or apoptosis. Pretreatment with BDNF- or EPO-antisense oligodeoxynucleotide (AS-ODN) reversed the ProT $\alpha$-induced inhibition of apoptosis, but not of necrosis (Figure 6d and Supplementary Figure 3). These results were consistent with the results for anti-BDNF or EPO IgG. However, 


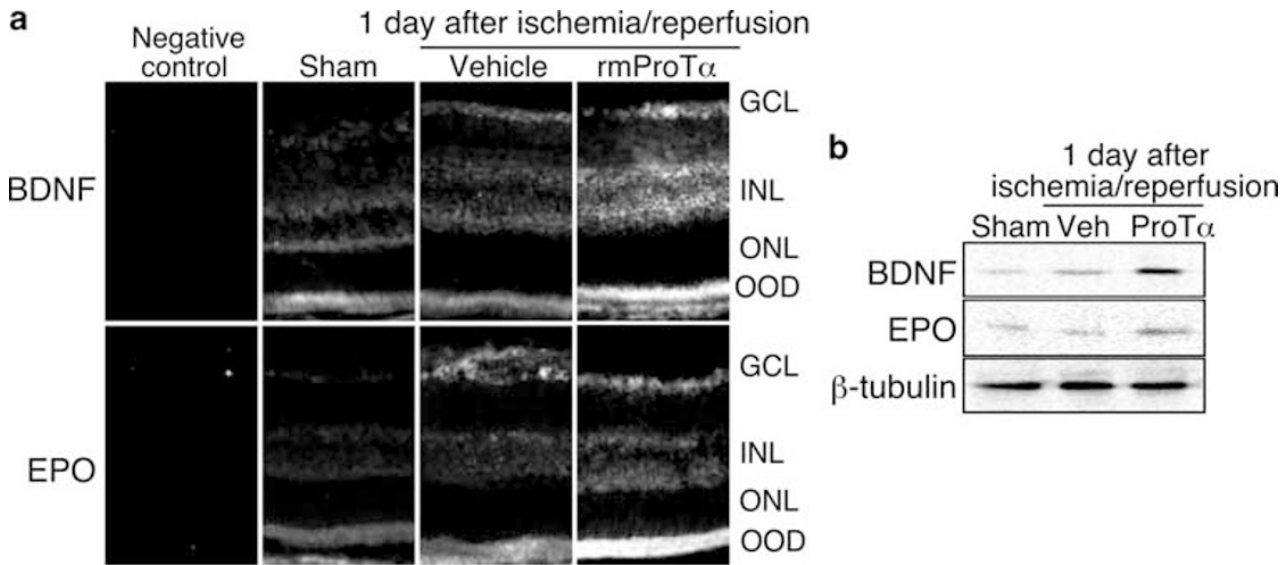

c

1 day after ischemia/reperfusion

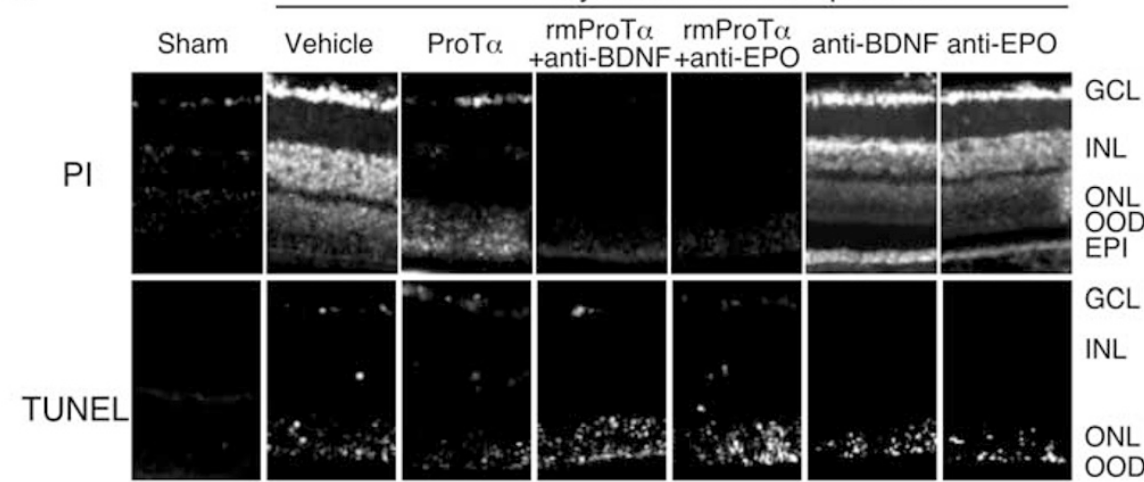

d

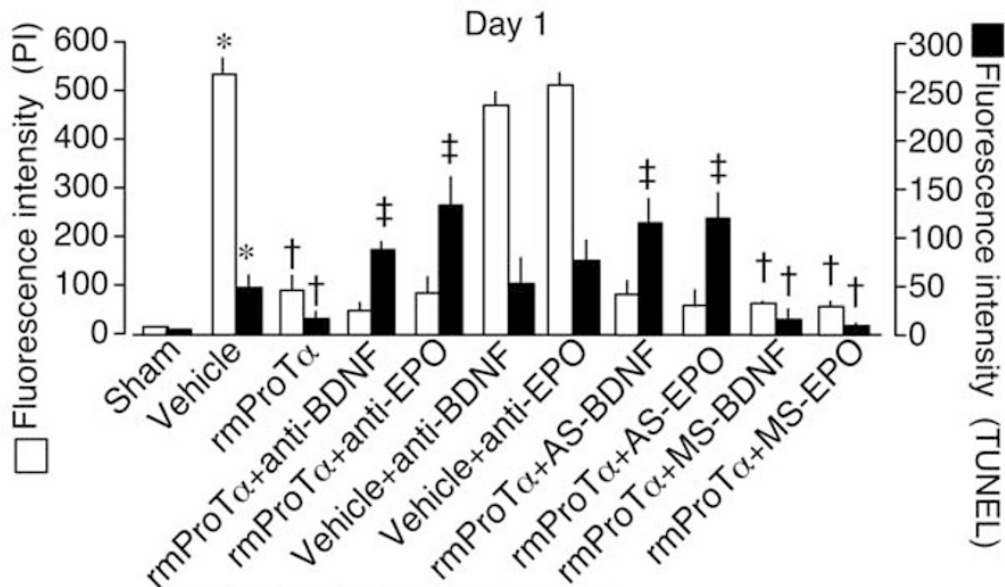

Ischemia/reperfusion

Figure 6 Involvement of neurotrophins in the ProT $\alpha$-induced retinal protection against ischemic damage. (a and $\mathbf{b})$ Enhanced expression of various neurotrophic factors after retinal ischemic stress with or without ProT $\alpha$. rmProT $\alpha(100 \mu \mathrm{g} / \mathrm{kg}$, i.v.) was administered $3 \mathrm{~h}$ after retinal ischemic stress. Immunostaining of retinas was carried out at $24 \mathrm{~h}$ after ischemia-reperfusion (a). Western blot analysis of BDNF and EPO in retinas at $24 \mathrm{~h}$ after ischemia-reperfusion (b). Results represent the means \pm S.E.M. of four independent experiments. (c) rmProT $\alpha$ (100 $\mu \mathrm{g} / \mathrm{kg}$ i.v.)-induced suppression of retinal ischemia-induced necrosis (PI staining) and apoptosis (TUNEL staining), and selective reversal of apoptosis by polyclonal anti-BDNF or polyclonal anti-EPO IgG. Anti-BDNF or anti-EPO IgG (1 $\mu$ g per eye) was i.vb. injected at 30 min before the ischemic stress. (d) Fluorescence intensities were analyzed using NIH ImageJ software. Results represent the means \pm S.E.M. of $4-6$ independent experiments. ${ }^{*} P<0.05$ versus sham. ${ }^{\dagger} P<0.05$ versus ischemia vehicle treatment. ${ }^{\ddagger} P<0.05$ versus ischemia rmProT $\alpha$ treatment

treatments with corresponding missense oligodeoxynucleotides (MS-ODNs) had no effect.

In vivo neuroprotective role of ProT $\alpha$ during retinal ischemia. As early as day 4 after ischemic stress, partial damage to retinal cells was observed in the GCL, INL, and ONL (Figure 7a and Table 2). I.vb pretreatment with an AS-ODN against ProT $\alpha$, but not with a mismatch scrambled MS-ODN, significantly worsened the damage at day 4 after ischemic stress. Similar results were also observed following 


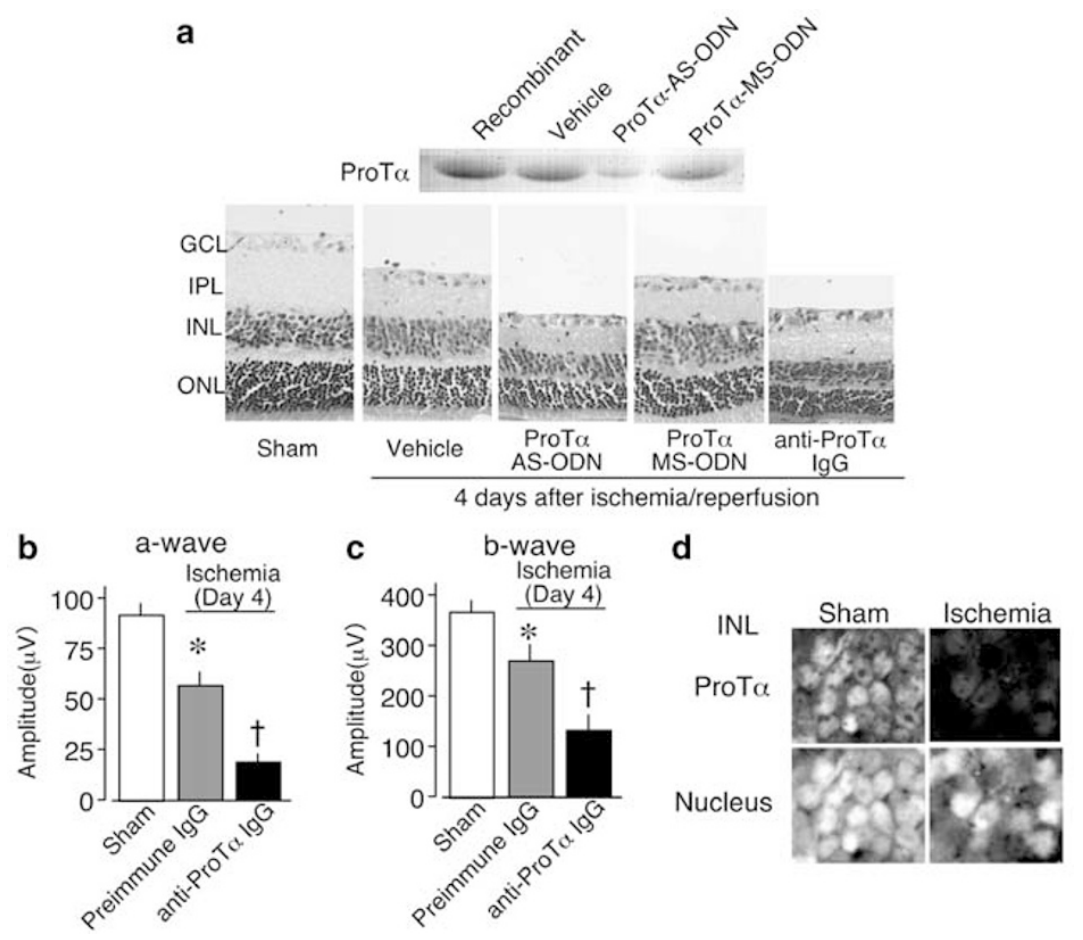

Figure 7 In vivo neuroprotective role of ProT $\alpha$ during retinal ischemia. (a) Worsening of retinal ischemic damage following treatment with anti-ProT $\alpha$ lgG (1 $\mu \mathrm{g} \mathrm{per} \mathrm{eye}$ $30 \mathrm{~min}$ before ischemic stress) or an AS-ODN for ProT $\alpha$. Retinas were isolated at day 4 after ischemic stress and used for histological studies. Upper panel: loss of ProT $\alpha$ protein in a retina pretreated with the AS-ODN, as evaluated by Gelcode Blue staining analysis. ${ }^{10}$ (b and $\mathbf{c}$ ) Functional worsening of the retinal ischemic damage following treatment with anti-ProT $\alpha \operatorname{lgG}$ or an AS-ODN for ProT $\alpha$ evaluated on the basis of a- (b) and b- (c) wave ERG analysis. The results represent the means \pm S.E.M. of six independent experiments. ${ }^{*} P<0.05$ versus sham. ${ }^{\dagger} P<0.05$ versus ischemia vehicle treatment. (d) Depletion of immunoreactive ProT $\alpha$ in the INL of the retina at $3 \mathrm{~h}$ after ischemia-reperfusion

Table 2 In vivo neuroprotective role of ProT $\alpha$ during retinal ischemia

\begin{tabular}{lcccc}
\hline Treatment & Days after ischemia/reperfusion & GCL & INL & ONL \\
\hline Sham+vehicle & 4 & $16.53 \pm 1.23$ & $128.71 \pm 5.93$ & $299.61 \pm 28.69$ \\
Ischemia+vehicle & 4 & $13.02 \pm 0.74$ & $111.54 \pm 2.96$ & $253.41 \pm 7.97^{*}$ \\
Ischemia+ProT $\alpha$ AS-ODN & 4 & $9.62 \pm 0.08^{\#}$ & $90.71 \pm 4.15^{\#}$ & $164.15 \pm 3.19^{\#}$ \\
Ischemia+ProT $\alpha$ MS-ODN & 4 & $13.62 \pm 0.58$ & $110.91 \pm 5.34$ & $266.10 \pm 7.97$ \\
Ischemia+ProT $\alpha$ IgG & 4 & $10.51 \pm 1.07^{\#}$ & $94.30 \pm 8.30^{\#}$ & $221.54 \pm 15.94^{\#}$ \\
\hline
\end{tabular}

Abbreviations: AS-ODN, antisense oligodeoxynucleotide; GCL, ganglion cell layer; IgG, immunoglobulin G; INL, inner nuclear layer; MS-ODN, missense oligodeoxynucleotide; ONL, outer nuclear layer

${ }^{\star} P<0.05$ versus sham; ${ }^{\#} P<0.05$ versus ischemia vehicle treatment

i.vb pretreatment ( $1 \mu \mathrm{g} / \mathrm{eye}, 30 \mathrm{~min}$ before ischemic stress) with anti-ProT $\alpha$ IgG, which absorbs ProT $\alpha,{ }^{10}$ which is released upon ischemic stress. In the ERG analysis, moreover, a weak but significant reduction in stimulationinduced a- and b-wave responses was observed at day 4 after the stress (Figure $7 \mathrm{~b}$ and $\mathrm{c}$ ). Anti-ProT $\alpha$ IgG injection further worsened the ischemia-induced functional damage. Moreover, the ProT $\alpha$-like immunoreactivities, which were observed in the nuclei of INL cells in the sham-operated retinas, completely disappeared without exception $3 \mathrm{~h}$ after the stress (Figure 7d).

\section{Discussion}

Prothymosin- $\alpha$, which is a highly acidic nuclear protein, is widely distributed throughout the body and is reported to play essential roles in the regulation of cell proliferation, as seen in the facts that ProT $\alpha$ upregulates c-Myc and selectively enhances estrogen receptor transcriptional activity by interacting with a repressor of estrogen receptor activity. ${ }^{17-22}$ Furthermore, ProT $\alpha$ interacts with histones and affects chromatin remodeling processes through histone acetyltransferases to promote and stabilize the interaction of ProT $\alpha$ with the oncoprotein SET/TAF-1 $\beta .^{23-25}$ Moreover, ProT $\alpha$ plays a cytoprotective role by inhibiting apoptosome formation in NIH3T3 cells subjected to apoptotic stress. ${ }^{26}$ Moreover, a recent report demonstrated that ProT $\alpha$ liberates Nrf2 from a Keap1-Nrf2 inhibitory complex under oxidative stress and contributes to Nrf2-dependent gene expression. ${ }^{27}$ In this mechanism, the transcription factor Nrf2 induces glutathione $S$-transferase, $\mathrm{NAD}(\mathrm{P}) \mathrm{H}$-quinone oxidoreductase (NQO1), $\gamma$-glutamylcysteine synthetase and heme oxygenese-1.

We recently reported that ProT $\alpha$, but not thymosin- $\alpha$, inhibits the necrosis of cortical neurons treated with ischemic 
or starvation stress. ${ }^{10}$ Under the condition of starvation stress, we found that membrane glucose transporters, such as GLUT1 and GLUT4, are internalized, thereby decreasing glucose transport in plasma membrane, leading to a rapid decrease in the intracellular adinosinetriphosphate (ATP) level. It should be noted that ProT $\alpha$ causes the apoptosis of cortical neurons in cultures subjected to starvation stress. As the addition of pyruvate, which inhibits necrosis by elevating cellular ATP levels, does not cause apoptosis in the same system, it is evident that ProT $\alpha$-induced necrosis-inhibition and apoptosis-induction can be attributed to independent mechanisms. ${ }^{28}$ However, this switch in cell death mode seems to have an important role in the protection of the brain in the event of stroke, as brain has potent anti-apoptosis systems, such as neurotrophins. ${ }^{11}$ Indeed, we have demonstrated that the concomitant addition of neurotrophins with ProT $\alpha$ completely inhibited neuronal death, at least for 3 days, in an in vitro culture system. ${ }^{10}$

The present study provides in vivo evidence for the ProT $\alpha$ induced switch in cell death mode. The first finding is that i.vb or systemic administration of ProT $\alpha$ completely blocked retinal damage at day 7 after ischemia. This prevention of cell death was observed throughout the retina, including in neural fibers (IPL and OPL) as well as in the GCL, INL and ONL, when ProT $\alpha$ was administered $30 \mathrm{~min}$ before, or at 3 and $24 \mathrm{~h}$ after ischemia. As ERG study also showed that retinal function was protected, it appears that ProT $\alpha$ has potential for use protecting against retinal damage. It is known that material transport into the retina from the blood is limited by the bloodretina barrier, as in the case of the blood-brain barrier. In the present study, systemic administration of biotinylated rmPro$\mathrm{T} \alpha$ was detected in the retina, with ischemia. This finding is consistent with the report that systemic administration (i.v.) of EPO (MW: 18,519), which has a greater MW than ProT $\alpha(\mathrm{MW}$ : $12,251)$, protects retinal neurons from ischemic damage. ${ }^{29}$ We have also reported the ischemia-dependent transport of Myc-tagged ProT $\alpha$ to the brain $30 \mathrm{~min}$ after systemic administration (i.v.). ${ }^{11}$ Thus, these findings suggest that damage to retinal capillary vessels by ischemic treatment allows the material to be freely transported.

The second finding is that necrosis occurs first and apoptosis later. In the present study, we used PI staining as a necrosis marker, although caspase-3 and TUNEL staining were used as apoptosis markers. The time course of necrosis and apoptosis incidents evaluated by TEM analysis clearly corresponded to that evaluated by PI staining and caspase-3 or TUNEL staining. We also found that there were no cortical neurons colabeled with PI-signal and caspase-3 (or TUNEL) signal following brain ischemia. ${ }^{11}$ Thus, these markers seem to be valid for the characterization of cell death modes. Our initial speculation was that cell death initiated by necrosis in the core expands because of the subsequent release of cytotoxic molecules causing more necrosis. However, this cell death expansion was terminated by the occurrence of apoptosis, in which microglia removed damaged cells without releasing cytotoxic molecules. Although systemic administration of ProT $\alpha$ thoroughly abolished both necrosis and apoptosis after retinal ischemia, the concomitant application of anti-BDNF or anti-EPO IgG with ProT $\alpha$ or pretreatment of BDNF or EPO AS-ODN with ProT $\alpha$ caused marked apoptosis as early as day 1 after the stress. However, these treatments alone had no effect on ischemia-induced cell death. As ProT $\alpha$ upregulated BDNF- and EPO-like immunoreactivities in the presence of ischemia, but not in its absence, ProT $\alpha$-induced apoptosis must have been inhibited at the same time by the upregulated neurotrophins. From these findings, it is evident that a ProT $\alpha$-induced switch in cell death mode occurs at day 1 , but the machineries that underlie the delayed apoptosis at day 3 and its inhibition by ProT $\alpha$ remain to be elucidated. There are reports showing that many other cytotoxic molecules, such as cytokines and NO, cause delayed apoptosis. $^{30,31}$ As the administered ProT $\alpha$ is unlikely to remain in the retina for 3 days, inhibition of delayed apoptosis by ProT $\alpha$ may be secondary to the initial prevention of rapid cell death, which may delay apoptosis through the production of cytotoxic molecules. Alternatively, the upregulation of neurotrophins by synergistic mechanisms induced by ProT $\alpha$ and ischemia may last for longer periods.

The major issue we addressed was whether or not ProT $\alpha$ has a neuroprotective role in ischemic retina. The present study successfully demonstrated that treatments with an AS-ODN against ProT $\alpha$ or anti-ProT $\alpha$ IgG worsened or accelerated retinal damage as detected by histochemistry and measurement of ERG functions. As ProT $\alpha$ was depleted from retinal cells upon ischemic stress, it is evident that released, not intracellular ProT $\alpha$ may afford retinal protection.

In conclusion, we demonstrated that ProT $\alpha$ inhibits necrosis of retinal cells, but causes apoptosis, which in turn is inhibited by endogenous and ProT $\alpha$-induced neurotrophins. Along with this gain-of-function study, we also modeled loss of function of ProT $\alpha$ by using an AS-ODN and anti-ProT $\alpha$ IgG. We found that ProT $\alpha$ appears to have therapeutic potential for treatment of acute retinal ischemia, as the therapeutic window of systemic ProT $\alpha$ was later than $3 \mathrm{~h}$ after ischemic stress.

\begin{abstract}
Materials and Methods
Preparation of recombinant proteins. Recombinant ProT $\alpha$ gene was amplified from cDNAs derived from mouse embryonic brains using specific primers: mouse $\quad 5^{\prime}$ primer, $5^{\prime}$-AACATATGTCAGACGCGGCAGTGGA-3'; $3^{\prime}$-primer, $5^{\prime}$-GGATCCAAGCTTGCTGTCTAGTCATCCTGG- ${ }^{\prime}$. The PCR products were cloned into pGEM-T Easy, and then subcloned into pET16b. BL21 (DE3) cells were transformed with $p E T 16 b$-ProT $\alpha$. Recombinant mouse ProT $\alpha$ were induced by $0.1 \mathrm{mM}$ isopropylthio- $\beta$-galactopyranoside, purified by acid phenol extraction ${ }^{32}$ and Biophoresis (ATTO, Tokyo, Japan) separation, and dialyzed against phosphatebuffered saline (PBS) for later use. The purified recombinant proteins were used in experiments involving mouse retina preparations.
\end{abstract}

Animals and induction of ischemia-reperfusion injury. Male ddY mice were purchased from Tagawa Experimental Animals (Nagasaki, Japan), and subjected to a modified method for retinal ischemia-reperfusion injury. Briefly, ddY mice $(30-40 \mathrm{~g})$ were anesthetized with an i1ntraperitoneal injection of sodium pentobarbital $(75 \mathrm{mg} / \mathrm{kg})$, and their pupils were fully dilated with $1 \%$ atropine sulfate drops. The anterior chamber was cannulated with a 33-gauge needle connected to a container of sterile intraocular irrigating solution (BSS PLUS dilution buffer; Alcon, Fort Worth, TX, USA). Retinal ischemia was induced by elevating the IOP to generate a hydrostatic pressure of $130 \mathrm{~mm} \mathrm{Hg}$ for $45 \mathrm{~min}$ by lifting the container. The retina was isolated at the indicated time points after ischemia-reperfusion treatment and the extent of damage was evaluated by hematoxylin and eosin staining. The numbers of cells for these measurements, taken in five adjacent areas (one area: $100 \mu \mathrm{m}$ ) within $1 \mathrm{~mm}$ of the optic nerve, were calculated (Tables 1 and 2). Data are the means \pm S.E.M. from 4 to 6 independent experiments. ProT $\alpha$ AS-ODN (5'-ATCGCCGCGTCTGACATGGT-3'), MS-ODN (5'-AGTGCAGCTTCGCACCTG GT- $\left.3^{\prime}\right)$, BDNF AS-ODN (5'-CATCACTCTTCTCACCTGGTGGAAC- $\left.3^{\prime}\right)$, MS-ODN 
(5'-GTTCCACCAGGTGAGAAGAGTGATG-3' $)^{33}$ EPO AS-ODN (5'-CTCACCGG GCACCCCCAT-3') and MS-ODN (5'-ATGGGGGTGCCCGGTGAG-3' $)^{34}$ were i.vb. injected ( $1 \mathrm{nmol}$ per eye) at 5,3 or 1 day before ischemic stress. Anti-BDNF or antiEPO antibody (Santa Cruz Biotechnology, Tokyo, Japan) were i.vb. injected a $30 \mathrm{~min}$ before ischemic stress. Animal care and experimental procedures were performed in accordance with conformed to the Guidelines for Animal Experimentation of Nagasaki University with the approval of the Institutional Animal Care and Use Committee.

Electroretinogram. The mice were tested after $3 \mathrm{~h}$ of dark adaptation. They were anesthetized with intraperitoneal pentobarbital sodium. Their pupils were dilated with $1 \%$ atropine. A contact electrode (KE-S; Kyoto contact lenses, Kyoto, Japan) was placed on the corneal apex and referenced to a needle electrode near the eye. The ground was a subdermal platinum needle electrode near the abdominal area. ERGs were produced by 20J flash intensities. The flash stimulus source (SLS-3100; Nihon Kohden, Tokyo, Japan) illuminated the eye by diffuse reflection off the interior surface of the ganzfeld. Maximum flash luminance was measured with detector (MEB-9104; Nihon Kohden, Tokyo, Japan). After the intensity series, an incandescent background light sufficient to desensitize the rod system was turned on, and ERGs produced by the standard stimulus were recorded every $2 \mathrm{~min}$ for $20 \mathrm{~min}$. The background was then turned off, and ERGs were produced by the standard stimulus every $2 \mathrm{~min}$ for the first $30 \mathrm{~min}$ of dark adaptation. The $a$ - and $b$-wave amplitudes were measured online (Neuropack $m$; QP-903B, Nihon Kohden, Tokyo, Japan).

Transmission electron microscopy. Retinas treated with ischemiareperfusion were fixed with $2.5 \%$ glutaraldehyde in $0.1 \mathrm{M}$ phosphate buffer $(\mathrm{pH} 7.4)$ for $1 \mathrm{~h}$ at $25^{\circ} \mathrm{C}$, postfixed with $1 \%$ osmium tetroxide for $1 \mathrm{~h}$ at $25^{\circ} \mathrm{C}$, dehydrated through a graded alcohol series and embedded in Epon812 resin. Ultrathin sections (80-nm thick) were cut with an Ultracut S (Leica, Vienna, Austria), and then stained with uranyl acetate and lead citrate for 30 and $5 \mathrm{~min}$, respectively. The stained sections were observed under an electron microscope (JEM-1210; JEOL, Tokyo, Japan). TEM analysis was used to characterize the cell death mode in the retinas at $24 \mathrm{~h}$ after the ischemia-reperfusion treatment. The numbers of necrotic and apoptotic cells for these measurements, taken in 30-50 adjacent areas (one area: $8 \times 12 \mu \mathrm{m}$ ) within $3 \mathrm{~mm}$ of the optic nerve, were calculated (Figures 2 and 3 ).

In vivo retinal PI staining. For PI (Sigma, Tokyo Japan) staining experiments, mice were anesthetized with sodium pentobarbital and i.vb. injected with PI (2 ng per eye) $1 \mathrm{~h}$ before collection of their retinas. The retinas were removed, fixed in $4 \%$ paraformaldehyde (PFA) in $\mathrm{K}^{+}$-free PBS and cryoprotected overnight in $25 \%$ sucrose in $\mathrm{K}^{+}$-free PBS. Retinas were fast-frozen in a cryoembedding compound on a mixture of ethanol and dry ice and stored at $-80^{\circ} \mathrm{C}$ until use. The retinas were cut into $10-\mu \mathrm{m}$ sections using a cryostat, thaw-mounted onto silane-coated glass slides and examined under a fluorescence microscope (Olympus, Tokyo, Japan). The fluorescence intensities of the PI-signals were quantified using NIH Image for Macintosh. The counting region of PI fluorescence intensities was from the GCL to the ONL, but not the EPI region because, in the EPI, PI signal was observed throughout the sham-operated retina, which is liable to be damaged and artificially stained with PI during the process of sample preparation.

Apoptosis staining of retinal sections. Retinal sections $(10 \mu \mathrm{m})$ were rinsed twice with PBS and reacted with TUNEL (Invitrogen, Tokyo Japan) solution from Roche Molecular Biochemicals for $1 \mathrm{~h}$ at $37^{\circ} \mathrm{C}$. They were washed twice in PBS and added to blocking buffer ( $1 \%$ bovine serum albumin (BSA) in PBS, pH 7.4) for $1 \mathrm{~h}$ at $25^{\circ} \mathrm{C}$, followed by incubation with streptavidin-fluorescein isothiocyanate (1:100; Vector Laboratories, Burlingame, CA, USA) for $1.5 \mathrm{~h}$ at $25^{\circ} \mathrm{C}$. Immunolabeled sections were mounted with Permafluor (Thermo Shandon, Pittsburgh, PA, USA), and examined under a fluorescence microscope (Olympus, Tokyo, Japan). Moreover, for active caspase-3 immunostaining, retinal sections $(10 \mu \mathrm{m})$ were rinsed twice with PBS and preincubated in blocking buffer (3\% BSA and $0.1 \%$ Tween 20 in PBS) for $1 \mathrm{~h}$ at $25^{\circ} \mathrm{C}$. Next, the sections were incubated with polyclonal anti-active caspase-3 $(1: 100$ dilution in blocking buffer; Cell Signaling, Tokyo, Japan) overnight at $4^{\circ} \mathrm{C}$, rinsed with PBS and incubated with Alexa 488conjugated anti-rabbit IgG (1:200 dilution; Invitrogen) for $2 \mathrm{~h}$ at $25^{\circ} \mathrm{C}$. Other sections were fixed with $4 \%$ PFA in PBS for $30 \mathrm{~min}$, and permeabilized with 50 and $100 \%$ methanol for 5 min each. Immunolabeled sections were mounted with Permafluor, and examined under a fluorescence microscope. The fluorescence intensities of the caspase-3 signals were quantified using NIH ImageJ software for Macintosh.

Western blot analysis. SDS-polyacrylamide gel electrophoresis using $10-12 \%$ polyacrylamide gels and immunoblot analysis was performed as described previously. ${ }^{28}$ Anti-BDNF, anti-EPO, anti-nerve growth factor and antibFGF IgG (1: 500; Santa Cruz Biotechnology) were used as the primary antibodies. Visualization of immunoreactive bands was performed using an enhanced chemiluminescent substrate (Super Signaling Substrate; Pierce Chemical Co., Rockford, IL, USA) for the detection of horseradish peroxidase. The specificity of polyclonal anti-BDNF and anti-EPO antibodies is described in the Supplementary text and Supplementary Figure 4

Statistical analysis. For statistical analysis of the data, Student's t-tests following multiple comparisons by analysis of variance were used. The criterion of significance was set at $P<0.05$. All results are expressed as means \pm S.E.M.

Acknowledgements. This study was supported by Grants-in-Aid for Scientific Research (to HU, B: 13470490 and 15390028), on Priority Areas - Research on Pathomechanisms of Brain Disorders (to HU, 17025031, 18023028, 20023022) from the Ministry of Education, Culture, Sports, Science and Technology (MEXT) and Encouragement of Young Scientists (to RF, B: 17790066 and 19790191) from the Japan Society for the Promotion of Science (JSPS). Also, Health and Labour Sciences Research Grants on Research on Biological Resources and Animal Models for Drug Development from Ministry of Health, Labour and Welfare (to HU, H2O-Research on Biological Resources and Animal Models for Drug Development003). We gratefully acknowledge A Akaike for technical advice in the retinal ischemia study, M Niwa and T Suematsu for technical assistance in the TEM studies and $\mathrm{H}$ Matsunaga, M Rikumaru, Y Kiguchi (Tobo) and S Kawakami for technical assistance with the retinal ischemia.

1. Dirnagl U, ladecola C, Moskowitz MA. Pathobiology of ischaemic stroke: an integrated view. Trends Neurosci 1999; 22: 391-397.

2. Lipton P. Ischemic cell death in brain neurons. Physiol Rev 1999; 79: 1431-1568.

3. Ueda H, Fujita R. Cell death mode switch from necrosis to apoptosis in brain. Biol Pharm Bull 2004; 27: 950-955.

4. Brines ML, Ghezzi P, Keenan S, Agnello D, de Lanerolle NC, Cerami C et al. Erythropoietin crosses the blood-brain barrier to protect against experimental brain injury. Proc Natl Acad Sci USA 2000; 97: 10526-10531.

5. Cheng Y, Deshmukh M, D'Costa A, Demaro JA, Gidday JM, Shah A et al. Caspase inhibitor affords neuroprotection with delayed administration in a rat model of neonatal hypoxic-ischemic brain injury. J Clin Invest 1998; 101: 1992-1999.

6. Gilgun-Sherki Y, Rosenbaum Z, Melamed E, Offen D. Antioxidant therapy in acute central nervous system injury: current state. Pharmacol Rev 2002; 54: 271-284.

7. Gladstone DJ, Black SE, Hakim AM. Toward wisdom from failure: lessons from neuroprotective stroke trials and new therapeutic directions. Stroke 2002; 33: 2123-2136.

8. Fujita R, Ueda H. Protein kinase C-mediated necrosis-apoptosis switch of cortical neurons by conditioned medium factors secreted under the serum-free stress. Cell Death Differ 2003; 10: 782-790.

9. Fujita R, Yoshida A, Mizuno K, Ueda H. Cell density-dependent death mode switch of cultured cortical neurons under serum-free starvation stress. Cell Mol Neurobiol 2001; 21: 317-324.

10. Ueda H, Fujita R, Yoshida A, Matsunaga H, Ueda M. Identification of prothymosin-alpha1, the necrosis-apoptosis switch molecule in cortical neuronal cultures. J Cell Biol 2007; 176 : 853-862.

11. Fujita $\mathrm{R}$, Ueda H. Prothymosin-alpha1 prevents necrosis and apoptosis following stroke. Cell Death Differ 2007; 14: 1839-1842.

12. Isenmann S, Kretz A, Cellerino A. Molecular determinants of retinal ganglion cell development, survival, and regeneration. Prog Retin Eye Res 2003; 22: 483-543.

13. Choi DW. Ischemia-induced neuronal apoptosis. Curr Opin Neurobiol 1996; 6: 667-672.

14. Lombardi G, Moroni F, Moroni F. Glutamate receptor antagonists protect against ischemiainduced retinal damage. Eur J Pharmacol 1994; 271: 489-495.

15. Block $F$, Schwarz $M$. The $b$-wave of the electroretinogram as an index of retinal ischemia. Gen Pharmacol 1998; 30: 281-287.

16. Unal Cevik I, Dalkara T. Intravenously administered propidium iodide labels necrotic cells in the intact mouse brain after injury. Cell Death Differ 2003; 10: 928-929.

17. Clinton M, Graeve L, el-Dorry H, Rodriguez-Boulan E, Horecker BL. Evidence for nuclear targeting of prothymosin and parathymosin synthesized in situ. Proc Natl Acad Sci USA 1991; 88: 6608-6612.

18. Gaubatz S, Meichle A, Eilers M. An E-box element localized in the first intron mediates regulation of the prothymosin alpha gene by c-myc. Mol Cell Biol 1994; 14: 3853-3862. 
19. Letsas KP. Frangou-Lazaridis M. Surfing on prothymosin alpha proliferation and antiapoptotic properties. Neoplasma 2006; 53: 92-96.

20. Martini PG, Delage-Mourroux R, Kraichely DM, Katzenellenbogen BS. Prothymosin alpha selectively enhances estrogen receptor transcriptional activity by interacting with a repressor of estrogen receptor activity. Mol Cell Biol 2000; 20: 6224-6232.

21. Pineiro A, Cordero OJ, Nogueira M. Fifteen years of prothymosin alpha: contradictory past and new horizons. Peptides 2000; 21: 1433-1446.

22. Segade F, Gomez-Marquez J. Prothymosin alpha. Int J Biochem Cell Biol 1999; 31: 1243-1248.

23. Gomez-Marquez J. Function of prothymosin alpha in chromatin decondensation and expression of thymosin beta-4 linked to angiogenesis and synaptic plasticity. Ann N Y Acad Sci 2007; 1112: 201-209.

24. Karetsou Z, Martic G, Tavoulari S, Christoforidis S, Wilm M, Gruss C et al. Prothymosin alpha associates with the oncoprotein SET and is involved in chromatin decondensation. FEBS Lett 2004; 577: 496-500.

25. Karetsou Z, Sandaltzopoulos R, Frangou-Lazaridis M, Lai CY, Tsolas O, Becker PB et al. Prothymosin alpha modulates the interaction of histone $\mathrm{H} 1$ with chromatin. Nucleic Acids Res 1998; 26: 3111-3118

26. Jiang X, Kim HE, Shu H, Zhao Y, Zhang H, Kofron J et al. Distinctive roles of PHAP proteins and prothymosin-alpha in a death regulatory pathway. Science 2003; 299 223-226.
27. Karapetian RN, Evstafieva AG, Abaeva IS, Chichkova NV, Filonov GS, Rubtsov YP et al. Nuclear oncoprotein prothymosin alpha is a partner of Keap1: implications for expression of oxidative stress-protecting genes. Mol Cell Biol 2005; 25: 1089-1099.

28. Fujita $\mathrm{R}$, Ueda $\mathrm{H}$. Protein kinase $\mathrm{C}$-mediated cell death mode switch induced by high glucose. Cell Death Differ 2003; 10: 1336-1347.

29. Junk AK, Mammis A, Savitz SI, Singh M, Roth S, Malhotra S et al. Erythropoietin administration protects retinal neurons from acute ischemia-reperfusion injury. Proc Natl Acad Sci USA 2002; 99: 10659-10664.

30. Tezel G, Wax MB. Increased production of tumor necrosis factor-alpha by glial cells exposed to simulated ischemia or elevated hydrostatic pressure induces apoptosis in cocultured retinal ganglion cells. J Neurosci 2000; 20: 8693-8700.

31. Toda N, Nakanishi-Toda M. Nitric oxide: ocular blood flow, glaucoma, and diabetic retinopathy. Prog Retin Eye Res 2007; 26: 205-238.

32. Evstafieva AG, Chichkova NV, Makarova TN, Vartapetian AB, Vasilenko AV, Abramov VM et al. Overproduction in Escherichia coli, purification and properties of human prothymosin alpha. Eur J Biochem 1995; 231: 639-643.

33. Mandolesi G, Menna E, Harauzov A, von Bartheld CS, Caleo M, Maffei L. A role for retinal brain-derived neurotrophic factor in ocular dominance plasticity. Curr Biol 2005; 15 2119-2124.

34. Liu J, Narasimhan P, Song YS, Nishi T, Yu F, Lee YS et al. Epo protects SOD2-deficient mouse astrocytes from damage by oxidative stress. Glia 2006; 53: 360-365.

\section{Supplementary Information accompanies the paper on Cell Death and Differentiation website (http://www.nature.com/cdd)}

